Int. J. Dev. Biol. 63: 9-15 (2019)

https://doi.org/10.1387/ijdb.180361fc

\title{
Smed-egfr-4 is required for planarian eye regeneration
}

\author{
ELENA EMILI", MACIÀ ESTEVE PALLARÈS\#, RAFAEL ROMERO and FRANCESC CEBRIÀ*,1 \\ Department of Genetics, Microbiology and Statistics, Faculty of Biology, University of Barcelona, Spain
}

\begin{abstract}
Planarians are remarkable organisms that can regenerate their entire body from a tiny portion thereof. This capability is made possible by the persistence throughout the lifespan of these animals of a population of pluripotent stem cells known as neoblasts. Planarian neoblasts include both pluripotent stem cells and specialized lineage-committed progenitors that give rise to all mature cell types during regeneration and homeostatic cell turnover. However, little is known about the mechanisms that regulate neoblast differentiation. A recent study demonstrated that Smed-egfr-1, a homologue of the epidermal growth factor receptor (EGFR) family, is required for final differentiation, but not specification, of gut progenitor cells into mature cells. Given the expression by planarians of several EGFR homologues, it has been proposed that these homologues may have diverged functionally to regulate the differentiation of distinct cell types in these animals. In this study, we investigated the role of Smed-egfr-4 in eye regeneration. Compared with controls, animals in which this gene was silenced by RNA interference (RNAi) regenerated smaller eyes. Moreover, the numbers of both mature eye cell types, photoreceptor neurons and cells of the pigment cup, were significantly reduced in Smed-egfr-4(RNAi)animals. By contrast, these animals exhibited an increase in the numbers of eye progenitor cells expressing the specific markers Smed-ovo and Smed-sp6-9. These results suggest that Smed-egfr-4 is required not for the specification of eye progenitor cells but for their final differentiation, and support the view that in planarians the EGFR pathway might play a general role in regulating the differentiation of lineage-committed progenitors.
\end{abstract}

KEY WORDS: planarian, regeneration, EGFR signalling, photoreceptor, stem cell differentiation

\section{Introduction}

Unravelling the mechanisms that regulate stem cell differentiation is crucial in order to understand the amazing regenerative capabilities of freshwater planarians, in which a population of stem cells is maintained for the entire lifespan and can be activated in response to injury or amputation. This remarkable ability makes freshwater planarians a classical model for the study of stem cell-based regeneration (for recent reviews, see Cebrià et al., 2018; Rink 2018). Planarian neoblasts are a heterogeneous cell population consisting of truly pluripotent undifferentiated stem cells, known as cNeoblasts (Wagner et al., 2011; Zeng et al., 2018), as well as specialized lineage-committed progenitors specific for distinct mature cell types (Scimone et al., 2014; Zhu and Pearson, 2016). Although the cell-specific progenitors of most cell types have been largely characterized, relatively little is known about the genes and signalling pathways that regulate the specification of these progenitors and their ultimate differentiation into mature cells (Zhu et al., 2015; Solana et al., 2013; Tu et al., 2015). It has been recently proposed that the epidermal growth factor receptor (EGFR) signalling pathway may play an important general role in neoblast differentiation (Barberán and Cebrià, 2018). Silencing of Smed-egfr-1 results in defects in planarian gut regeneration and maintenance (Barberán et al., $2016 a$ ), reducing the number of newly differentiated mature gut cells and increasing the number of gut progenitors that fail to differentiate. Smed-egfr-1 therefore appears necessary not for gut progenitor specification but for their ultimate differentiation (Barberán et al., 2016a). In planarians, the EGFR family has undergone expansion and 6 homologues have been identified in the model species Schmidtea mediterranea (Barberán et

Abbreviations used in this paper: EGFR, epidermal growth factor receptor; RNAi, RNA interference.

\footnotetext{
*Address correspondence to: Francesc Cebrià. Departament de Genètica, Microbiologia i Estadística, Facultat de Biologia, Universitat de Barcelona, Spain. e-mail: fcebrias@ub.edu -Tel. +34-934021499 - web: http://www.ub.edu/planaria - (iD) https://orcid.org/0000-0002-4028-3135
}

\#Note: Both authors contributed equally to this work 
al., 2016b). It has been proposed that these different EGFRs, which show distinct expression patterns, participate in the differentiation of a variety of cell types, including neurons and protonephridia (Fraguas et al., 2011; Rink et al., 2011). Given the role of Smed-egfr-1 in gut differentiation, the fact that distinct EGFR homologues are expressed in different tissues and cell types, and the implication of certain EGFRs in cell differentiation, one recently proposed model suggests that EGFRs play a general role in the final differentiation of different populations of lineage-committed progenitors (Barberán and Cebrià, 2018). In the present study, we investigated the role of Smed-egfr-4 in eye regeneration. We found that silencing of Smed-egfr-4 led to the formation of smaller eyes consisting of fewer photoreceptor neurons and pigment cup cells. Interestingly, this reduction in the number of mature eye cells correlated with an increase in the number of eye progenitors. These results suggest that Smedegfr-4 is required for the final differentiation of eye progenitor cells and support a general role of EGFR genes in planarian neoblast differentiation.
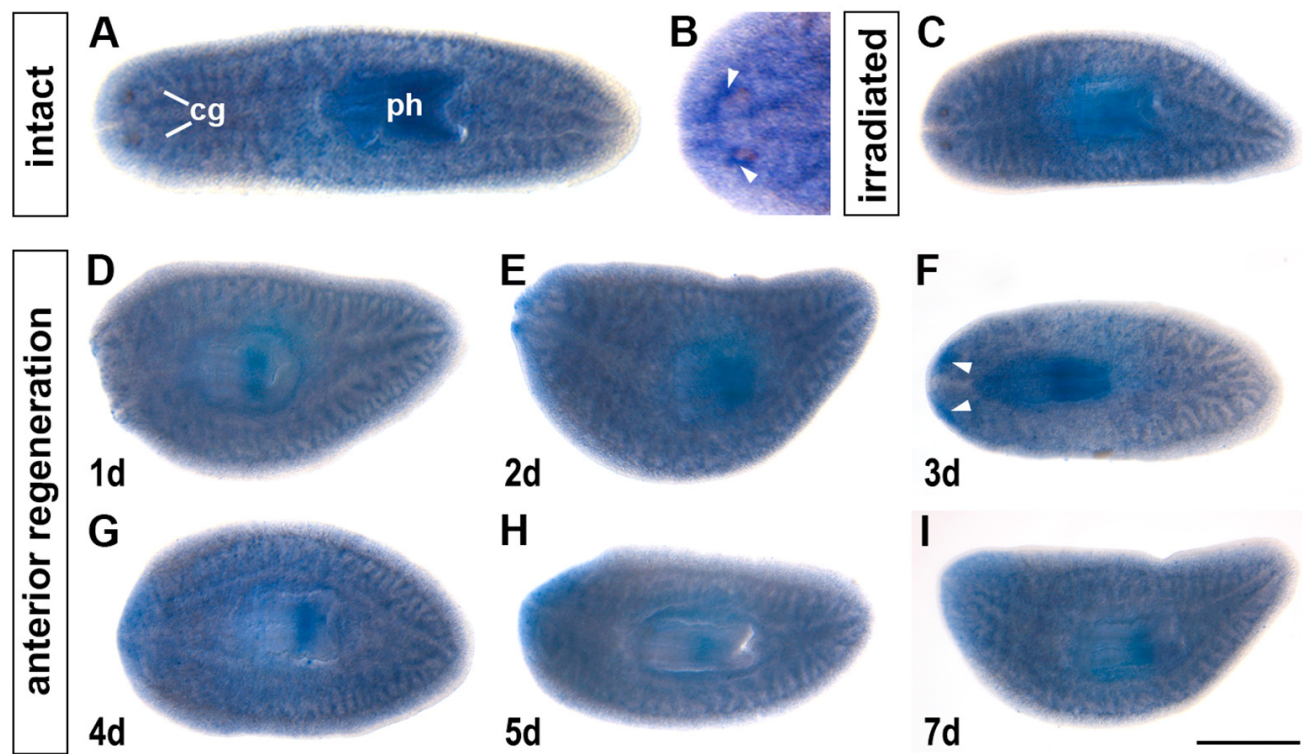

H

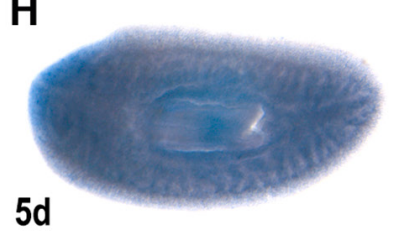

J
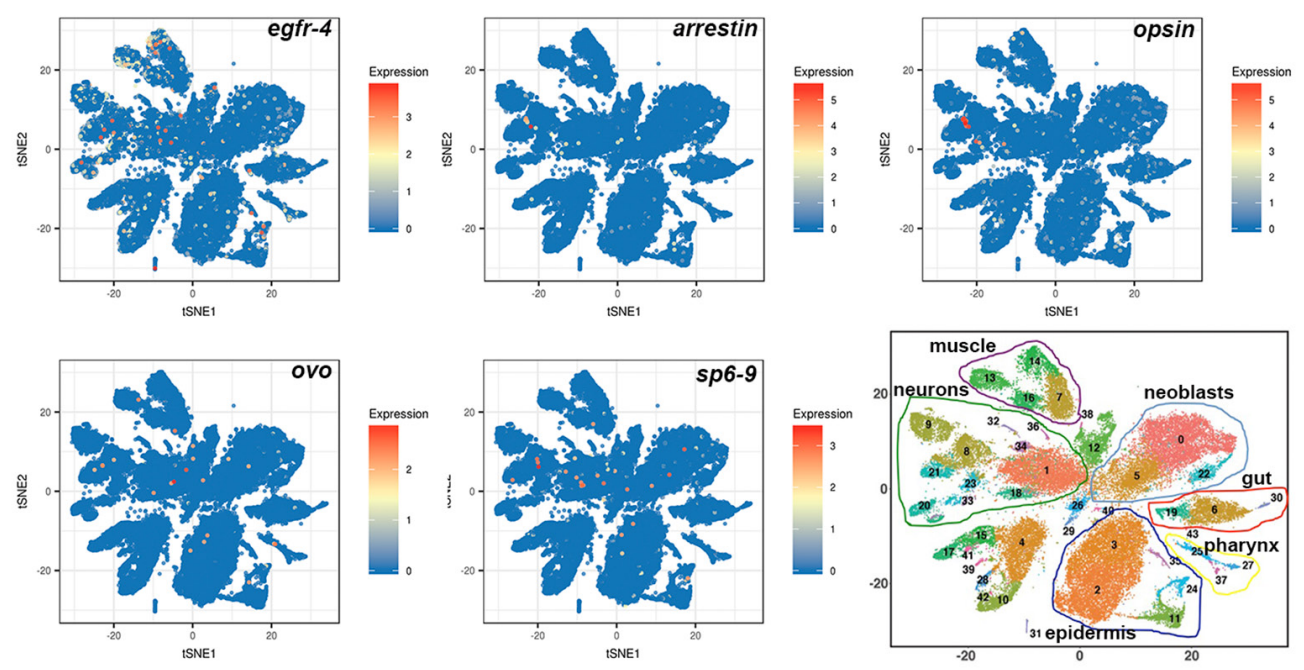

\section{Results}

Smed-egfr-4 is expressed ubiquitously, including in the eyes

To characterize the expression pattern of Smed-egfr-4, we performed in situ hybridization experiments in intact planarians. Whole-mount in situhybridization revealed Smed-egfr-4expression in the cephalic ganglia, the pharynx, and the mesenchyme around the gut branches (Fig. 1A). Low levels of expression were also detected in photoreceptor cells (Fig. 1B). The expression pattern in the mesenchyme did not appear to correspond to neoblasts, since the Smed-egfr-4 pattern was unchanged in animals in which the neoblast population was eliminated by irradiation (Fig. 1C). To evaluate Smed-egfr-4 expression during regeneration, planarians were decapitated and the regeneration of a new head was monitored. Smed-egfr-4 was expressed in the regenerative blastema from day 1 after amputation (Fig. 1D). From days 2-3, Smed-egfr-4 was also detected in the newly formed brain primordia (Fig. 1 E-F) and high levels of expression were maintained within the blastema and in the regenerating cephalic ganglia throughout the entire regenerative process (Fig. $1 \mathrm{G}-\mathrm{I}$ ).

Recently, two single-cell RNAseq atlas of $S$. mediterranea have been published (Fincher et al., 2018; Plass et al., 2018). Searches in them showed that Smed-egfr-4 is expressed in a variety of tissues (in agreement with in situ hybridizations), including: neurons, muscle, gut, pharynx and epidermis (Fig. 1J). Also, Smed-egfr-4 was found to be expressed in neoblasts (Fig. 1J). The fact that Smed-egfr-4 seems to be expressed at low levels in neoblasts together with its higher expression in many other tissues could explain why its overall pattern after irradiation did not show obvious differences compared to that from non-irradiated animals (Fig. 4 A,C).

As the signal of Smed-egfr-4in the photoreceptors after in situhybridiza-

Fig. 1. Smed-egfr-4 expression in intact and regenerating planarians. $(\mathbf{A}, \mathbf{B})$ Smed-egfr-4 is expressed in the CNS, pharynx, and mesenchyme, and in photoreceptors (arrowheads in B). (C) Irradiation has no obvious effect on the pattern of Smed-egfr-4 expression. (D-I) Smed-egfr-4 expression during anterior regeneration. Arrowheads in (F) indicate the new brain primordia. (J) $t$-SNE plots foregfr-4, arrestin (dd_Smed_ v6_17854_0_1; Brandletal., 2015), opsin (dd_Smed_v6_15036_0_1; Brandl et al., 2015), ovo (dd_Smed_v6_48430_0_1; Brandlet al., 2015) and sp6-9 (dd_Smed_ v6_17385_0_1; Brandl et al., 2015) obtained from http://digiworm.wi.mit. edu (Fincher et al., 2018). cg, cephalic ganglia; ph, pharynx. Scale bar, $400 \mu \mathrm{m}$. 
tions was faint we searched to compare its expression profile in the single-cell RNAseq atlas with that from other well-known genes expressed in the eyes such as arrestin, opsin, ovo and sp6-9 (Fig. $1 \mathrm{~J})$. Although no specific eye lineage has been identified in this single cell atlas, all these genes are expressed in cells within the neural cluster as Smed-egfr-4 does. Therefore, if we combine the
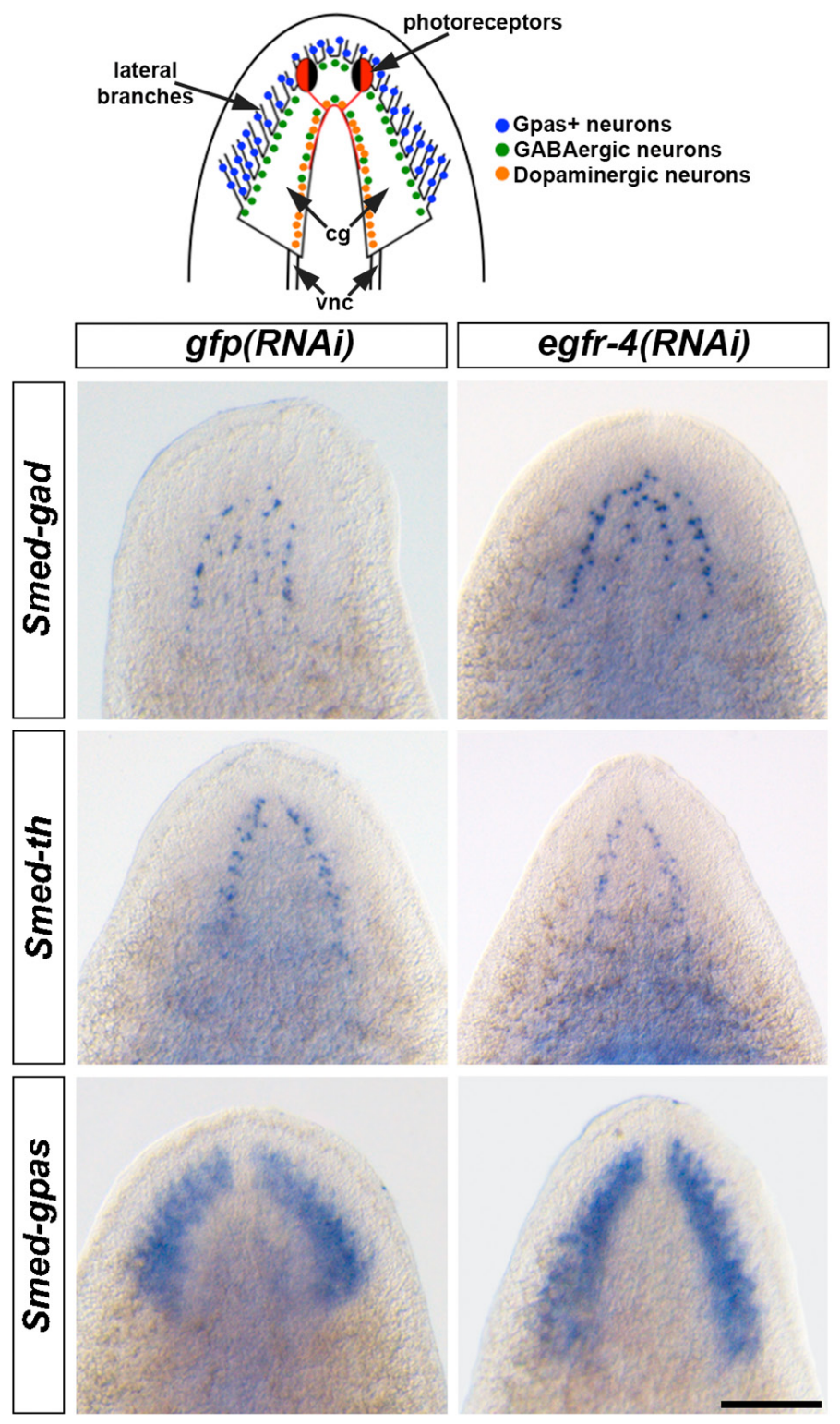

expression data from in situ hybridizations and the single-cell atlas with the RNAi phenotype on eye regeneration described below, it seems quite probable that Smed-egfr-4 is expressed in a variety of tissues including the photoreceptors.

\section{Smed-egfr-4 silencing has no detectable effect on CNS regeneration}

To characterize the function of Smed-egfr-4, we performed a series of functional RNAi experiments. Because Smed-egfr-4 is expressed in the central nervous system (CNS), we first investigated whether its silencing resulted in defective regeneration of the cephalic ganglia. Whole-mount in situ hybridization for different neural-specific markers showed that Smed-egfr-4(RNAI) animals correctly regenerated the CNS, displaying normal patterns of expression of the different neuronal subpopulations analysed (Fig. 2), including GABAergic neurons (Smed-gad, Nishimura et al., 2008), dopaminergic neurons (Smed-th, Nishimura et al., 2007), and the brain lateral branches (Smed-gpas, Cebrià et al., 2002).

\section{Smed-egfr-4 silencing results in the regeneration of smaller eyes}

Planarian eyes consist of two distinct cell types, which can be
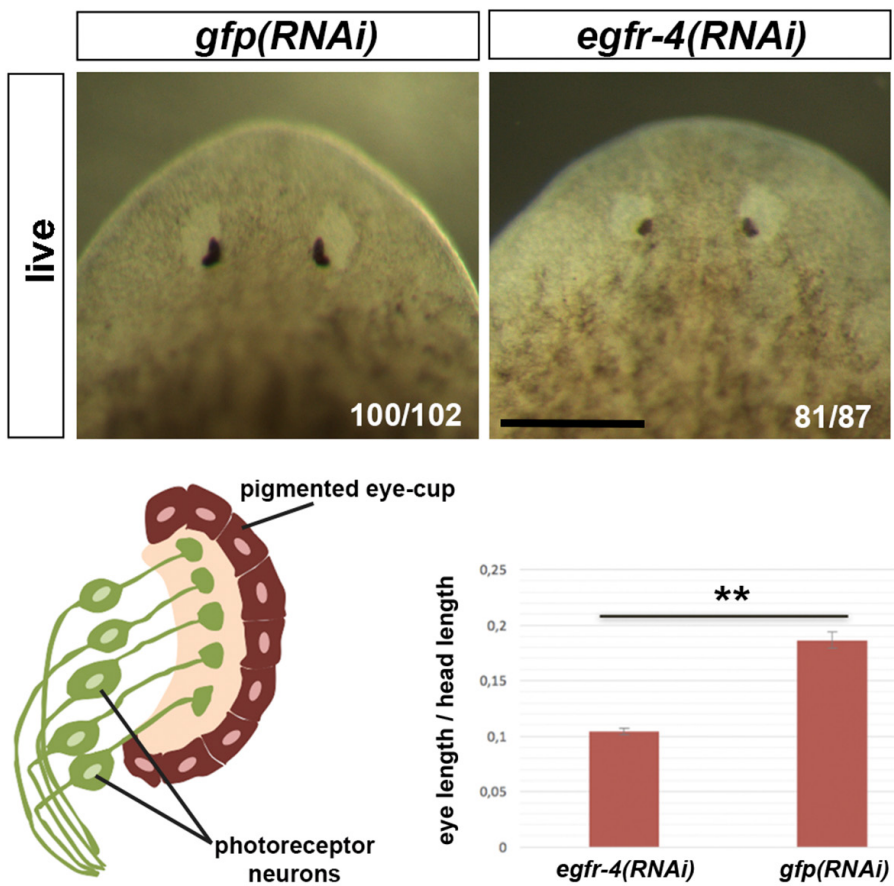

Fig. 2 (left). Normal CNS regeneration after Smed-egfr-4 RNAi. In Smed-egfr-4(RNAi) planarians, the normal patterns of each of the different neuronal populations are re-established after 11 days of regeneration. The schematic drawing represents the cephalic ganglia with the relative positions of the neural markers used below Smed-gad: GABAergic neurons; Smed-th: dopaminergic neurons and Smed-gpas: G protein alpha subunit positive neurons. Smed-gad is expressed in neurons around the central neuropil with a higher density in the outer side of the cephalic ganglia. Smed-th is expressed in neurons mainly located along the medial side of the cephalic ganglia. Smed-gpas is expressed in neurons located in the cephalic lateral branches that project towards the head periphery. The photoreceptor neurons with their axonal projections are shown in red. cg, cephalic ganglia; vnc, ventral nerve cords. Scale bar, $150 \mu \mathrm{m}$.

Fig. 3 (right). Smed-egfr-4(RNAi) planarians regenerate smaller eyes. Smed-egfr-4 silencing results in the regeneration of smaller eyes during anterior regeneration. The schematic drawing shows the organization of the planarian eye with their two cell types: the pigmented eye-cup and the bipolar photoreceptor neurons that send rhabdomeric projections towards the pigmented eye-cup and axonal processes that project together into a specific brain region. The graph depicts the ratio of eye length to head length, measured from the base of the eye to the anterior tip of the head. $n=40$ eyes per treatment. ${ }^{*} p<0.005$ (Student's t-test). Error bars correspond to s.e.m. All samples correspond to 11 days of regeneration. Scale bar, 200 um. 
easily distinguished in live animals: photoreceptor neurons and pigment eye-cup cells. Photoreceptor neurons are located in the whitish area adjacent to the eye pigment cup (Fig. 3). Given our observation that Smed-egfr-4 is expressed in photoreceptor cells, we investigated the effects of a reduction in its expression on eye regeneration. Direct visual examination revealed that the eyes regenerated by Smed-egfr-4(RNAi) planarians were smaller than those of controls. To quantitatively characterize these apparent differences, and to account for the correlation between head and eye size (bigger heads have bigger eyes and smaller heads have smaller eyes), we measured the ratio of eye length to head length (measured from the posterior base of the eyes to the anterior most tip of the head). The measurements obtained confirmed that Smedegfr-4 silencing resulted in the regeneration of smaller eyes (Fig. 3).

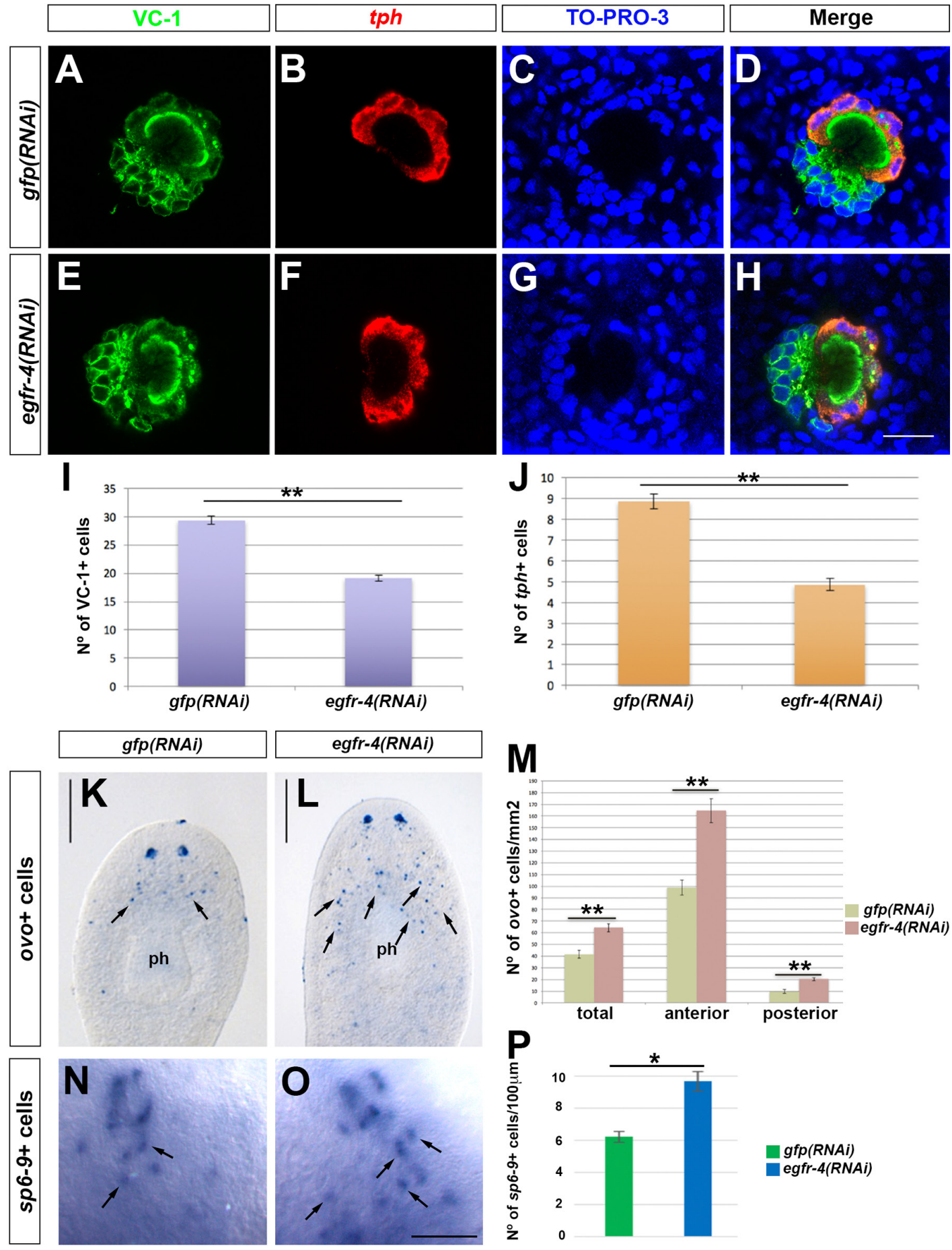

Fig. 4. Smed-egfr-4RNAiresults in a decrease in the number of mature eye cells and an increase in the number of eye progenitor cells. (A-H) Double fluorescent in situ hybridization for Smed-tph and immunostaining with VC-1 to detect cells of the pigment cup (in red) and photoreceptor neurons (in green) in control gfp(RNAi) (A-D), and Smed-egfr-4(RNAi) animals (E-H). Nuclear staining with TO-PRO-3 is shown in blue. Only Z-stacks of very few confocal planes are shown to clearly see the cellular organization and architecture of the eye. Scale bar, $20 \mu \mathrm{m}$. (I, J) Graphs depicting the numbers of $\mathrm{VC}-1+$ and tph + cells, respectively. $\operatorname{In}(\mathbf{I}), n=23$ eyes per treatment. $\ln (\mathbf{J}), n=15$ eyes per treatment ${ }^{* *} p<0.005$ (Student's t-test). All samples correspond to 11 days of regeneration. $(\mathbf{K}, \mathbf{L})$ Whole-mountin situ hybridization for Smed-ovo. Arrows indicate eye progenitor cells in the prepharyngeal region. ph, pharynx. Scale bar, $300 \mu \mathrm{m}$. (M) Graph depicting the numbers of ovo+ cells throughout the organism. Total refers to the entire organism; anterior refers to the region between the tip of the head and the base of the pharynx; posterior refers to the region between the base of the pharynx and the posterior tip of the tail. All samples correspond to 10 days of regeneration. $n=20$ animals per treatment. ${ }^{*} p<0.005$ (t-test). $(\mathbf{N}, \mathbf{O})$ Whole-mount in situ hybridization for Smed-sp6-9. Arrows

indicate some eye progenitor cells in the pre-pharyngeal region. Scale bar, $40 \mu \mathrm{m}$. (P) Graph depicting the number of sp6-9+ cells in each condition. All samples correspond to 11 days of regeneration. $n=25$ animals per treatment. ${ }^{*} p<0.05$ (Student's t-test). In all graphs error bars correspond to s.e.m. 


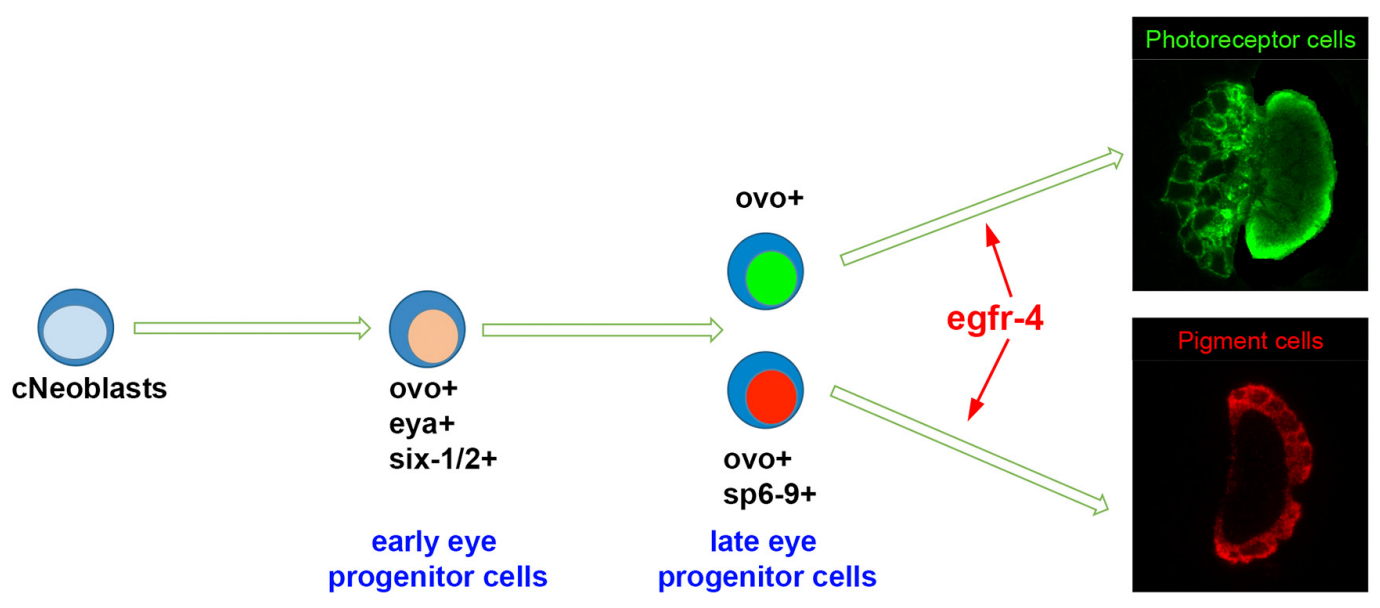

Fig. 5. Proposed model illustrating the role of Smed-egfr-4in eye regeneration. See details within the main text.

\section{Smed-egfr-4(RNAi) animals regenerate fewer mature eye cells but more eye progenitors}

Given that Smed-egfr-4(RNAi) planarians regenerated smaller eyes, we investigated whether this effect corresponded to a reduction in the number of eye cells. VC-1 is an anti-arrestin antibody that specifically recognizes planarian photoreceptor neurons (Sakai et al., 2000). Smed-tph encodes a tryptophan hydroxylase homologue that is expressed in the cells of the eye pigment cup (Fraguas et al., 2011). The cell bodies of photoreceptor neurons are clustered around the eye pigment cup. Thus, to quantify the number of photoreceptors and eye pigment cup cells we performed double in situ hybridization and immunostaining for Smed-tph and VC1, respectively (Fig. $4 \mathrm{~A}-\mathrm{H}$ ). Although the architecture of the eye and the organization of the photoreceptors and eye pigment cup cells was rather normal (Fig. $4 \mathrm{~A}-\mathrm{H}$ ), quantifications revealed a significant reduction in the numbers of both cell types after Smedegfr-4 RNAi (Fig. 4 I-J).

Smed-ovo labels is expressed in both mature and progenitor eye cells (Lapan and Reddien, 2012). Eye progenitor cells are distributed as two trails of cells located posterior to the mature eyes, and differentiate with increasing proximity to the mature eye (Lapan and Reddien, 2012). To determine whether the decrease in the number of mature eye cells induced by Smed-egfr-4 silencing was caused by a reduction in the number of eye progenitors, we examined the effect of Smed-egfr-4RNAi on Smed-ovo expression. Remarkably, in contrast to the effect on mature cells, we observed an increase in the number of Smed-ovo+cells in Smed-egfr-4(RNAi) planarians (Fig. 4K-L). In control planarians, Smed-ovo+cells were predominantly located between the mature eyes and the base of the pharynx. However, after Smed-egfr-4 silencing, the distribution of Smed-ovo+ cells shifted to more posterior regions (Fig. 4 $\mathrm{K}-\mathrm{L}$ ). Quantification of the number of Smed-ovo+ cells revealed a significant increase in Smed-egfr-4(RNAi)animals (Fig. 4M). While Smed-ovo is expressed in progenitors of both photoreceptor neurons and pigment cup cells, Smed-sp6-9 is selectively expressed in the progenitors of the pigment cup cells (Lapan and Reddien 2011, 2012). Smed-egfr-4 silencing also resulted in a significant increase in the number of Smed-sp6-9 cells (Fig. $4 \mathrm{~N}-\mathrm{P}$ ). Together, these results indicate that $S m e d-e g f r-4$ does not contribute to the specification of pluripotent neoblasts into eye progenitors, but is most probably involved in regulating the final differentiation of these progenitors into mature eye cells.

\section{Discussion}

Recently, planarians are emerging as an excellent model in which to study stem cell differentiation in vivo. Planarian pluripotent stem cells give rise to lineage-committed progenitors, which in turn subsequently differentiate into all the cell types found in these animals (Scimone et al., 2014; Zhu and Pearson, 2016). While little is known about how this differentiation process is regulated at the molecular level, several genes that participate in neoblast differentiation have been identified. For example, Smed-mex-3 is required for specification of the different progenitor populations (Zhu et al., 2015), while silencing of Smed-not impairs neoblast differentiation (Solana et al., 2013).

Planarian eyes consist of two cell types: pigmented cells, which organize themselves to form the pigment eye-cup; and bipolar photoreceptor neurons, which send rhabdomeric dendrites to the cells of the eye pigment cup and visual axons to a medio-lateral region of the brain. Moreover, some visual axons project contralaterally crossing the midline and forming the optic chiasm (Sasaki et al., 2000; Okamoto et al., 2005). Recently, transcriptomic analysis of planarian eyes identified several genes that regulate the differentiation of pluripotent neoblasts to form eye progenitor cells and ultimately mature eye cells. The earliest progenitors committed to the eye lineage co-express Smed-ovo, Smed-six-1/2, and Smedeya. Silencing of any of these genes inhibits eye regeneration (Pineda et al., 2000; Mannini et al., 2004; Lapan and Reddien 2012). It appears that both photoreceptor neurons and pigmented eye-cup cells are derived from a split in the lineage of these ovor early progenitors (Lapan and Reddien, 2012). Furthermore, not all photoreceptor neurons appear to be equal, as several subpopulations (anterior, dorsal posterior, and ventral posterior) can be distinguished based on their expression of specific markers (Collins et al., 2010). Interestingly, Smed-smad6/7-1 and Smed-bmp are involved in the differentiation of the anterior photoreceptor neurons (González-Sastre et al., 2012).

In this study, we investigated the role of Smed-egfr-4in planarian regeneration. Despite its expression in the CNS, silencing of this gene had no effect on CNS regeneration, suggesting that other EGFRs may compensate for the lack of Smed-egfr-4 function. However, we cannot rule out the possibility that Smed-egfr-4 silencing gave rise to defects in the CNS that could not be detected with the markers we used. Our analysis revealed that Smed-egfr-4 silencing 
did result in significant decreases in both types of mature eye cells. Remarkably, this decrease was coupled with an increase in the number of Smed-ovo+ and Smed-sp6-9+ progenitor cells located in the pre-pharyngeal region (Fig. 4). According to one current model of eye differentiation, pluripotent neoblasts (cNeoblasts) give rise to early eye progenitors that co-express ovo, eya, and six-1/2 (Lapan and Reddien, 2012), and from which the two eye lineages are derived, subsequently giving rise to late eye progenitors. Those expressing ovo, sp6-9, and other factors give rise to the cells of the eye pigment cup, whereas those expressing ovo and other factors give rise to photoreceptor neurons (Lapan and Reddien, 2012). This posterior-to-anterior differentiation "gradient" might explain in part why after the silencing of Smed-egfr-4 there is an increase of ovo+ cells that reach more posterior regions that the sp6-9+ cells that also increase in number after the silencing of this gene, but remain in more relative anterior regions. The fact that Smed-egfr-4 silencing interferes with the final differentiation of both lineages (photoreceptor neurons and cells of the eye pigment cup) and increases the numbers of ovo+and sp6-9+cells suggests that Smed-egfr-4 is required for the differentiation of both lineages following their divergence from a common early progenitor (Fig. 5). This putative autonomous role of Smed-egfr-4 in eye progenitor differentiation is in line with that previously described for Smed-egfr-1 during gut progenitor differentiation (Barberán et al., 2016a), and supports the view that the EGFR signalling pathway in planarians might play a general role in the differentiation of lineage-committed progenitors (Barberán and Cebrià, 2018). Further studies will be required to identify the other factors involved in the final differentiation of late eye progenitors and to better characterize the contributions of other EGFRs to the differentiation of other planarian cell types.

\section{Materials and Methods}

\section{Planarian culture}

Asexual S. mediterranea from the $\mathrm{BCN}-10$ clonal line were used in all experiments. Animals were fed with veal liver and starved for at least 1 week before all experiments. All experiments were done at $20^{\circ} \mathrm{C}$.

\section{RNA interference}

RNA interference (RNAi) was performed as previously described (Sánchez Alvarado and Newmark, 1999). Control animals were injected with green fluorescent protein (GFP)-derived double-stranded RNA (dsRNA). All animals underwent two rounds of dsRNA injection and amputation, separated by $3-4$ days.

\section{In situ hybridization and immunohistochemistry}

For whole-mount in situ hybridizations, animals were treated as previously described (King and Newmark, 2013). In order to visualize photoreceptor neurons, fluorescent in situ hybridization for Smed-tph was followed by immunostaining using the monoclonal antibody VC-1 $(1: 15,000)$ (Sakai et al., 2000), and an Alexa 488-conjugated goat anti-mouse secondary antibody (1:400; Molecular Probes). TO-PRO-3 was used for nuclear staining. A Leica MZ16F stereomicroscope and a ProgRes C3 camera (Jenoptik) were used for analysis of non-fluorescent in situ hybridizations. Fluorescence images were captured using a Leica SPE confocal microscope. All images were processed and analysed using ImageJ and Photoshop.

\section{Statistical analyses}

Statistical analyses were performed using Microsoft Excel and R Software 3.5-0 (RStudio 1.1.453). All results are expressed as the mean e standard error of the mean (s.e.m.). Data were analysed by Student's t-test and a p-value $<0.05$ was considered statistically significant. All quantifications were performed by an observer blind to treatment conditions.

\section{Acknowledgements}

We would like to thank all members of our laboratory, especially Susanna Fraguas and Sara Barberán for their help and technical support. We thank Emili Saló for critically reading the manuscript. We thank Owen Howard and Carolina Isiegas for advice on English style. This work was funded by grant BFU2015-65704P from the Ministerio de Economía y Competitividad (Spain) to F.C.

\section{References}

BARBERÁN, S., FRAGUAS, S., CEBRIÀ, F. (2016a). The EGFR signaling pathway controls gut progenitor differentiation during planarian regeneration and homeostasis. Development 143: 2089-2102.

BARBERÁN, S., MARTíN-DURÁN, J.M., CEBRIÀ, F. (2016b). Evolution of the EGFR pathway in Metazoa and its diversification in the planarian Schmidtea mediterranea. Sci Rep 6: 28071.

BARBERÁN, S., CEBRIÀ, F. (2018). The role of the EGFR signalling pathway in stem cell differentiation during planarian regeneration and homeostasis. Semin Cell Dev Biol doi: 10.1016/j.semcdb.2018.05.011.

BRANDL, H., MOON, H., VILA-FARRÉ, M., LIU, S.-Y., HENRY, I., RINK, J. (2015). PlanMine - a mineable resource of planarian biology and biodiversity. Nuc Acid Res gkv1148. doi:10.1093/nar/gkv1148.

CEBRIÀ, F., NAKAZAWA, M., MINETA, K., IKEO, K., GOJOBORI, T., AGATA, K (2002). Dissecting planarian central nervous system regeneration by the expression of neural-specific genes. Dev Growth Differ 44: 135-146.

CEBRIÀ, F., ADELL, T., SALÓ, E. (2018). Rebuilding a planarian: from early signalling to final shape. Int J Dev Biol 62: 537-550.

COLLINS, J.J. 3rd, HOU, X., ROMANOVA, E.V., LAMBRUS, B.G., MILLER, C.M. SABERI, A., SWEEDLER, J.V., NEWMARK, P.A. (2010). Genome-wide analyses reveal a role for peptide hormones in planarian germline development. PLoS Biol 8: e1000509.

FINCHER, C.T., WURTZEL, O., DE HOOG, T., KRAVARIL, K.M., REDDIEN, P.W. (2018). Cell type transcriptome atlas for the planarian Schmidtea mediterranea. Science 360: eaaq1736.

FRAGUAS, S., BARBERÁN, S., CEBRIÀ, F. (2011). EGFR signaling regulates cell proliferation, differentiation and morphogenesis during planarian regeneration and homeostasis. Dev Biol 354: 87-101.

GONZÁLEZ-SASTRE, A., MOLINA, M.D., SALÓ, E. (2012). Inhibitory Smads and bone morphogenetic protein (BMP) modulate anterior photoreceptor cell number during planarian eye regeneration. Int J Dev Biol 56: 155-163.

KING, R.S., NEWMARK, P.A. (2013). In situ hybridization protocol for enhanced detection of gene expression in the planarian Schmidtea mediterranea. BMC Dev Biol 13: 8.

LAPAN, S.W., REDDIEN, P.W. (2011). dlx and sp6-9 control optic cup regeneration in a prototypic eye. PLoS Genet 7: e1002226.

LAPAN, S.W., REDDIEN, P.W. (2012). Transcriptome analysis of the planarian eye identifies ovo as a specific regulator of eye regeneration. Cell Rep 2: 294-307.

MANNINI, L., ROSSI, L., DERI, P., GREMIGNI, V., SALVETTI, A., SALÓ, E., BATISTONI, R. (2004). Djeyes absent (Djeya) controls prototypic planarian eye regeneration by cooperating with the transcription factor Djsix-1. Dev Biol 269: 346-359.

NISHIMURA, K., KITAMURA, Y., INOUE, T., UMESONO, Y., SANO, S., YOSHIMOTO, K., INDEN, M., TAKATA, K., TANIGUCHI, T., SHIMOHAMA, S., AGATA, K. (2007). Reconstruction of dopaminergic neural network and locomotion function in planarian regeneration. Dev Neurobiol 67: 1059-1078.

NISHIMURA, K., KITAMURA, Y., UMESONO, Y., TAKEUCHI, K., TAKATA, K., TANIGUCHI, T., AGATA, K. (2008). Identification of glutamic acid decarboxylase gene and distribution of gabaergic nervous system in the planarian Dugesia japónica. Neuroscience 153: 1103-1114.

OKAMOTO, K., TAKEUCHI, K., AGATA, K. (2005). Neural projections in planarian brain revealed by fluorescent dye tracing. Zoolog Sci 22: 535-546.

PINEDA, D., GONZÁLEZ, J., CALLAERTS, P., IKEO, K., GEHRING, W.J., SALÓ, E. (2000). Searching for the prototypic eye genetic network: Sine oculis is essential for eye regeneration in planarians. Proc Natl Acad Sci USA 97: 4525-4529. 
PLASS, M., SOLANA, J., WOLF, F.A., AYOUB, S., MISIOS A., GLAZAR, P., OBERMAYER, B., THEIS, F.J., KOCKS, C., RAJEWSKY, N. (2018). Cell type atlas and lineage tree of a whole complex animal by single-cell transcriptomics. Science 360: eaaq1723.

RINK, J.C. (2018). Stem cells, patterning and regeneration in planarians: selforganization at the organismal scale. Methods Mol Biol 1774: 57-172.

RINK, J.C., VU, H.T., SÁNCHEZ-ALVARADO, A. (2011). The maintenance and regeneration of the planarian excretory system are regulated by EGFR signaling. Development 138: 3769-3780.

SAKAI, F., AGATA, K., ORII, H., WATANABE, K. (2000). Organization and regeneration ability of spontaneous supernumerary eyes in planarians -eye regeneration field and pathway selection by optic nerves-. Zoolog Sci 17: 375-381.

SÁNCHEZ ALVARADO, A., NEWMARK, P.A. (1999). Double-stranded RNA specifically disrupts gene expression during planarian regeneration. Proc Natl Acad Sci USA 96: 5049-5054.

SCIMONE, M.L., KRAVARIK, K.M., LAPAN. S.W., REDDIEN, P.W. (2014a). Neoblasts specialization in regeneration of the planarian Schmidtea mediterranea. Stem Cell Reports 3: 339-352.
SOLANA, J., GAMBERI, C., MIHAYLOVA, Y., GROSSWENDT, S., CHEN, C., LASKO P., RAJEWSKY, N., ABOOBAKER, A. (2013). The CCR4-NOT complex mediates deadenylation and degradation of stem cell mRNAs and promotes planarian stem cell differentiation. PLoS Genet 9: e1004003.

TU, K.C., CHENG, L.C., VU, H.T., LANGE, J.J., McKINNEY, S.A., SEIDEL., C.W., SÁNCHEZ-ALVARADO, A. (2015). Egr-5 is a post-mitotic regulator of planarian epidermal differentiation. eLife 4: e10501.

WAGNER, D.E., WANG, I.E., REDDIEN, P.W. (2011). Clonogenic neoblasts are pluripotent adult stem cells that underlie planarian regeneration. Science332:811-816.

ZENG, A., LI, H., GUO, L., GAO, X., McKINNEY, S., WANG, Y., YU, Z., PARK J., SEMERAD, C., ROSS, E., CHENG, L.C., DAVIES, E., LEI, K., WANG, W., PERERA, A., HALL, K., PEAK, A., BOX, A., SÁNCHEZ ALVARADO, A. (2018). Prospectively isolated tetraspanin+ neoblasts are adult pluripotent stem cells underlying planaria regeneration. Cell 173: 1593-1608.

ZHU, S.J., PEARSON, B.J. (2016). (Neo)blast from the past: new insights into planarian stem cell lineages. Curr Opin Genet Dev 40: 74-80.

ZHU, S.J., HALLOWS, S.E., CURRIE, K.W., XU, C., PEARSON, B.J. (2015). A mex3 homolog is required for differentiation during planarian stem cell lineage development. eLife 4: e07025. 


\section{Further Related Reading, published previously in the Int. J. Dev. Biol.}

Planaria: an animal model that integrates development, regeneration and pharmacology Oné R. Pagán

Int. J. Dev. Biol. (2017) 61: 519-529

https://doi.org/10.1387/ijdb.160328op

The planarian $\mathbf{P} 2 \mathrm{X}$ homolog in the regulation of asexual reproduction

Toshihide Sakurai, Hayoung Lee, Makoto Kashima, Yumi Saito, Tetsutaro Hayashi, Tomomi Kudome-Takamatsu, Osamu Nishimura, Kiyokazu Agata and Norito Shibata

Int. J. Dev. Biol. (2012) 56: 173-182

https://doi.org/10.1387/ijdb.113439ts

Regeneration of neuronal cell types in Schmidtea mediterranea: an immunohistochemical and expression study Susanna Fraguas, Sara Barberán, Begoña Ibarra, Linda Stöger and Francesc Cebrià

Int. J. Dev. Biol. (2012) 56: 143-153

https://doi.org/10.1387/ijdb.113428sf

Heterogeneity of planarian stem cells in the S/G2/M phase

Sören Moritz, Franziska Stöckle, Claudia Ortmeier, Henning Schmitz, Gustavo RodríguezEsteban, Göran Key and Luca Gentile

Int. J. Dev. Biol. (2012) 56: 117-125

https://doi.org/10.1387/ijdb.113440sm

Planarian regeneration: a classic topic claiming new attention

Emili Saló and Kiyokazu Agata

Int. J. Dev. Biol. (2012) 56: 1-4

https://doi.org/10.1387/ijdb.123495es

The planarian neoblast: the rambling history of its origin and some current black boxes Jaume Baguñà

Int. J. Dev. Biol. (2012) 56: 19-37

https://doi.org/10.1387/ijdb.113463jb

Planarian regeneration: achievements and future directions after 20 years of research Emili Saló, Josep F. Abril, Teresa Adell, Francesc Cebriá, Kay Eckelt, Enrique FernándezTaboada, Mette Handberg-Thorsager, Marta Iglesias, M Dolores Molina and Gustavo Rodríguez-Esteban

Int. J. Dev. Biol. (2009) 53: 1317-1327

https://doi.org/10.1387/ijdb.072414es
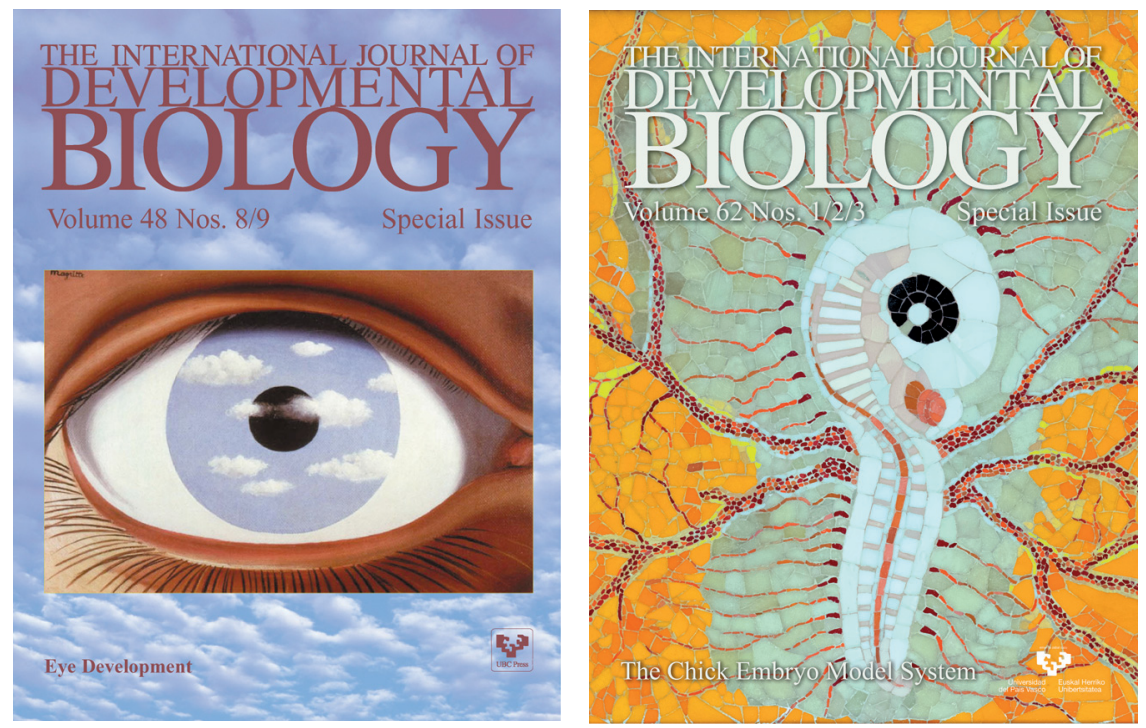
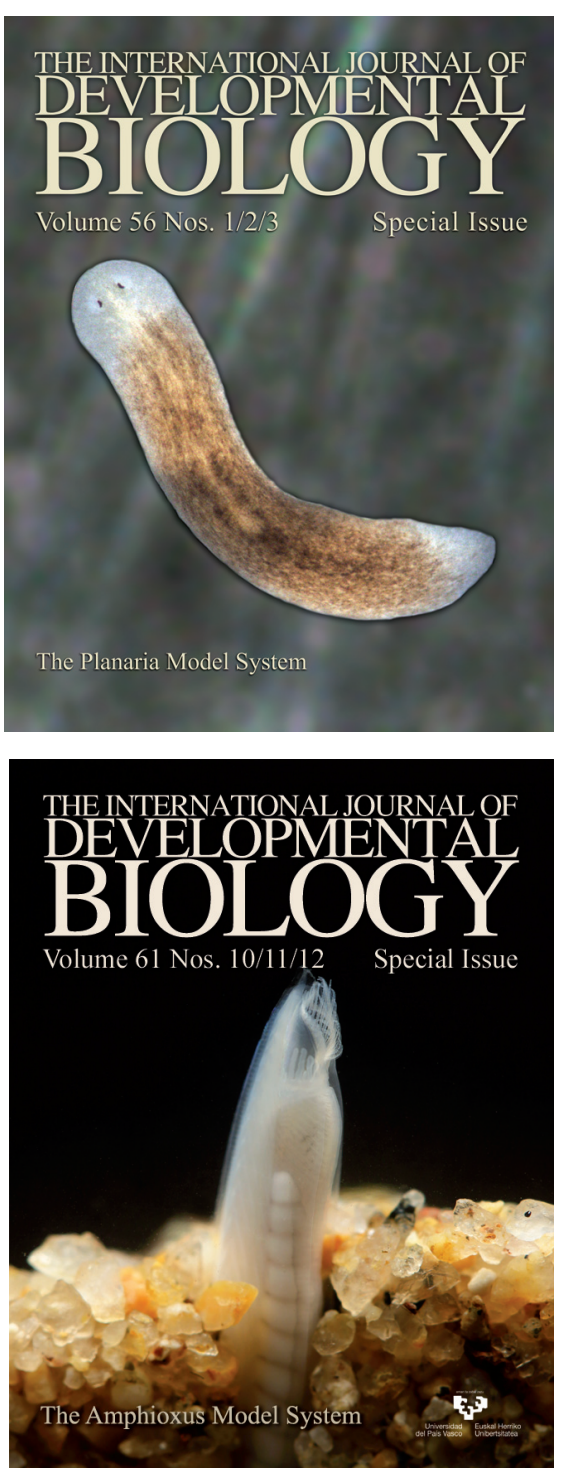